\title{
PREGNANT WOMEN'S GRAPHIC REPRESENTATIONS: A NEW INSTRUMENT FOR THE ASSESSMENT OF THE BODY IMAGE DURING GESTATION
}

\author{
Maria Eduarda S. Carvalho \\ CESEM-NOVA-FCSH, Portugal \\ educarte@sapo.pt \\ João M. R. M. Justo \\ Faculdade de Psicologia, Universidade de Lisboa, Portugal
}

Fecha de Recepción: 21 Julio 2018

Fecha de Admisión: 1 Octubre 2018

\begin{abstract}
Pregnant women's body image is crucial for psychological organization during pregnancy. Projective drawings enable the assessement of body image but studies using drawings of pregnancy (DP) are scarce. Aims: to observe the evolution of body image between the second and the third trimesters using DP and the relationships between DP and sociodemographic and clinical factors. Participants: pregnant women waiting for sonograms (202, second trimester; 159, third trimester). Instruments: Sociodemographic and Clinical Questionnaire and DP. Results: DP's data at the second trimester were factoranalyzed yelding four factors: F1- General Representation of the Imaginary Baby $(\alpha=.966)$, F2- Representation of the Maternal Image $(\alpha=.888)$, F3- Detailed Representation of the Imaginary Baby $(\alpha=.846)$ and F4- Recognition of Pregnancy $(\alpha=.588)$. Between the two moments, F2 presented a significant difference while F1, F3 and F4 did not. Significant correlations were observed between DP's factors and clinical variables: parity, spontaneous abortions, total of abortions and the beginning of maternal perception about fetal movements. Conclusion: in a healthy population, DP are sensitive to changes in maternal image. Once the imaginary baby representation and the recognition of pregnancy do not change significantly, the theory of psychological development during pregnancy is reinforced.
\end{abstract}

Keywords: pregnancy; drawings of pregnancy; imaginary baby; maternal body image; pregnancy recognition

\section{BACKGROUND}

A major aspect of the self restructuring during pregnancy is the working through of body image (Mendes, 2002). Based at the Drawing a Person Test (Machover, 1949), research underlined projective drawings of body image during pregnancy (Tolor \& Digrazia, 1977) and of the projection of 


\section{PREGNANT WOMEN'S GRAPHIC REPRESENTATIONS: A NEW INSTRUMENT FOR THE ASSESSMENT OF THE BODY IMAGE DURING GESTATION}

the imaginary baby (Parquet \& Delcambre, 1980; Sá \& Biscaia, 2004) in the sequence of the theoretical work of Lebovici (1983).

Despite the present lack of papers about drawing techniques during pregnancy, recent studies based at interviews support the importance of assessing pregnant women's body image: a) body image during pregnancy undergoes important changes related with expectations about future body changes in the perinatal period (Watson et al., 2016); b) acceptance of changes in body image is associated with recognition of the pregnant body (Watson et al., 2016); c) anatomic changes like abdomen and breasts salience are important about satisfaction with the body (Watson et al., 2015); d) late in pregnancy, the working through conflicts between the image of the ideal female body and the image of maternal body (including the baby) are fundamental for maternal adjustment (Chang et al., 2006) and e) a correlation exists between attitudes about body image in gestation and prenatal maternal attachment (Huang et al., 2004). Once these studies are based at self-report methodologies it seems crucial to deepen the study of maternal body image using drawing techniques.

Body image during pregnancy may be related with the three developmental phases happening in pregnancy and proposed by Colman and Colman (1971): acceptance, differentiation and separation. These phases may become operational through drawings' elements: a) acceptance - recognition of details of pregnancy (prominent maternal womb, fetus inside maternal womb, uterus, placenta and umbilical cord), b) differentiation - limits between fetal image and maternal image and the differentiation of the fetal shape and c) separation - fetal cephalic presentation evidencing closeness with delivery or the baby outside the maternal body as an anticipation of the future real baby. Drawings may reflect fetal differentiation and maternal-fetal bonding; showing the pregnant body, drawings become indicators of recognition and acceptance of body and of identity changes in pregnancy (Sá \& Biscaia, 2004).

In drawings of pregnancy, the representation of the maternal-container, of the baby-content and of the relationship between both may highlight Bion's (1963) container-content model at which Raphaell-Leff's (2009) based the "placental paradigm" of gestation underlining the different ways of mother-baby contact and differentiation. Studies show elements of drawings suggestive of pregnancy acceptance: nakedness, transparency (with or without fetal visibility), genitalia, large breasts and prominent waists, hips and abdomens (Tolor \& Digrazia, 1977). Parquet and Delcambre (1980) underlined elements of affective expression related to maternal-fetus differentiaton and bonding like representation of umbilical cord, placenta, facial expression and expressive elements related with emotional states of the characters. Swan-Foster and colleagues (2003) showed that gestational age and fetus' morphologic evolution are not predictive of the projective representation of pregnancy.

Significant differences emerge according with parity (Riazuelo, 2010). In first pregnancies, the representation about the baby seems much more phantasized (facial and clothes details). In second pregnancies, drawings are more realistic and show aspects about the recognition of pregnancy (placentas, umbilical cords, foetus in cephalic position). This also happens in the sequence of previous traumatic experiences in previous pregnancies (Riazuelo, 2004).

The drawing of pregnancy, in the present research, is based in studies about the projective use of drawings (Harris, 1981; Kolck, 1984) in both healthy and risk pregnancies (Sá \& Biscaia, 2004; Parquet \& Delcambre, 1980; Swan-Foster, Foster, \& Dorsey, 2003; Tolor \& Digrazia, 1977).

Studies in this domain are inconsistent about the consigne: "I would like you to draw your pregnancy" (Sá \& Biscaia, 2004); "Draw yourself as being pregnant" (Silva, 2006) and "Draw your self as pregnant", "Draw a fear or a conflict", "Give to fear what it needs", "Draw your pregnancy story" (Swan-Foster, Foster, \& Dorsey, 2003).

About evaluation criteria, Biscaia (1990) and Biscaia and Sá (1996) use objective criteria (location of drawing at the paper sheet, size of the drawing and human figures present at the drawing) 
and subjective elements (quality of the human figure like facial or body kinesthesia, global affective expression, level of differentiation between maternal and baby's image, baby's place relatively to maternal image, baby's gender and acknowledgement of pregnancy in an anatomical way or in an affective way).

\section{Aim and Hypothesis}

It is intended to use the drawings of pregnancy to create indicators related to the body image of the pregnant woman during the second and the third trimesters of pregnancy once that mother-fetus differentiation is supposed to happen after the end of the first trimester. It is hoped that these indicators may contribute for the development of research in psychology of pregnancy; namely about the maternal acceptance of the body image during gestation, the maternal perception of the inside baby, the maternal anticipation of delivery and the prediction of the future mother-infant relationship. It would also be interesting to observe if these indicators are related or not to sociodemographic and clinical variables.

Significant differences are expected between the second and the third trimesters in indicators related to: a) maternal body image, b) maternal representation about the baby's body and c) the baby's position.

Between the second and the third trimesters, no differences are expected about: a) maternal recognition of pregnancy and b) the differentiation between mother's image and fetus' image.

\section{METHOD}

\section{Study design, participants and procedure}

In order to test the hypothesis, it was decided to perform a longitudinal study. Participants were pregnant women waiting for sonograms at an institution for obstetrical diagnosis, Centro Ecográfico de Entrecampos, Lisboa, Portugal. This project was ethically evaluated by the institutions's border of directors. Participants were informed about the research's goals and methods and verbal informed consent was obtained. Data recollection was performed at a first moment by the second trimester and at a second moment by the third trimester (Carvalho, 2011). Of the 213 women invited to participate, 211 accepted (refusal rate, $.94 \%$ ). When the drawing of pregnancy was asked, 9 participants refused reducing the number of drawings to 202. Because of changes in personal agenda, hospitalization or preterm delivery, at the second moment 22 participants were absent and only 189 were interviewed (attrition rate, 11.64\%). Among these 189 participants, 30 refused to participate at the drawings of pregnancy and only 159 accepted.

\section{Inclusion and exclusion criteria}

In order to get a healthy sample, participants that could present characteristics related to obstetrical risks were excluded: pregnant adolescents, pregnancies in an older age, single pregnant women, twin pregnancies and obstetrical high risk pregnancies. Being so, pregnant women above 19 years old at the second trimester of pregnancy and living with the father of the future baby were included.

\section{Measures}

Sociodemographic and Clinical Questionnaire At the first moment, the Sociodemographic and Clinical Questionnaire (about participants, partners, and obstetrical aspects of the present and of previous pregnancies) was applied and after that participants were asked to draw their body images during gestation. 
The drawing of pregnancy (DP) At the second moment, the drawing of pregnancy was asked once more. Pregnant women were asked to draw according to the consigne: "Draw yourself as pregnant". An A4 sheet of white paper, pencil number 2 and rubber were offered to participants.

At both moments, several other questionnaires were applied about the psychic organization of the pregnant woman (Carvalho, 2011). Interviews were performed by the first author.

In order to perform a quantitative analysis of drawings, it was decided to creat a scale; the Drawing of Pregnancy Scale (DPS). Two main areas were identified: maternal image and fetal/baby image.

At the first evaluation moment, women were between 20 and 24 weeks of gestation $(M=22.02$, $S D=.9)$. At the second moment, women were between 28 and 37 weeks of gestation $(M=31.92$, $\mathrm{SD}=1.68)$. Sociodemographic characteristics are displayed at Table 1. Most of the subjects were Portuguese and all the others spoked Portuguese fluently and were living in Portugal. The majority was married and almost all of the others were living with their partners out of wedlock; cohabitation with the father of the baby started before pregnancy. Educational level was of high ranking and occupational level was at the two first categories of Graffar (1956) classification system (93.6\%). Only $3.96 \%$ of participants had special visual and graphic skills.

Table 2 displays data about the obstetric history of the participants as well as data about the present pregnancy. Only $4 \%$ of the sample had voluntary abortions and only once. The majority $(83 \%)$ referred no spontaneous abortions while $17 \%$ reported one to three. Only $4 \%$ reported being submitted to an abortion by medical advice.

Relatively to the present pregnancy, Table 3 presents information about investment of pregnancy, risk factors, past traumatic events and aspects related with the future baby.

Usually participants desired and planned pregnancy and refered no traumatic events nor risk factors. Most part $(79.6 \%)$ knew the baby's gender and reacted positively to it. Due to reduction of participants between the first $(n=202)$ and the second moment $(n=159)$, significant changes were observed: traumatic events $\left(\chi^{2}=18.88, p<.001\right)$ and baby's gender $\left(\chi^{2}=.18, p<.001\right)$. Non significant differences were found in: nationality $\left(\chi^{2}=2.37, .1<p<.2\right)$; marital status $\left(\chi^{2}=.06, .8<\right.$ $p<.9)$; occupational level $\left(\chi^{2}=2.15, .1<p<.2\right)$; desire of pregnancy $\left(\chi^{2}=3.53, .05<p<.1\right)$; planned pregnancy $\left(\chi^{2}=.02, .9<p<.8\right)$; risk factors $\left(\chi^{2}=.12, .7<p<.8\right)$; preference about baby's gender $\left(\chi^{2}=.18, .5<p<.7\right)$; baby's name already choosed $\left(\chi^{2}=.7>p>14.8\right)$. For other variables, differences about means were not computable because values were to similar: age, education, marital life long, previous pregnancies, parity, voluntary abortions, spontaneous abortions, abortions by medical advice, gestational age at the first moment, previous sonograms, medical appointments, gestational age at the first consultation and beginning of perception of fetal movements.

\section{RESULTS}

\section{Building the Drawing of Pregnancy Scale}

According to the hypothesis, indicators about maternal image and about fetal/baby image were needed. For each one of these aspets, items were generated about: image, shape, place (baby), profile (mother), pregnancy details and body details (face, eyes, mouth, nose, hair, head-body differentiation, upper limbs, lower limbs, feet and hands). The two groups of items of the DPS were evaluated in a dichotomous way (present vs. absent). A descriptive analysis of all identified categories was performed and next it was done an analysis of differences item by item between drawings at the two moments of evaluation. At the first moment, the majority of participants represented the baby inside the maternal womb in a non-fetal position. The image of the fetus emerges as a human figure with a low degree of differentiation observable between head and trunk, lower and upper limbs, face, hands, eyes, mouth, nose and hair, and with total absence of feet and sex. 
About maternal figure, the majority of participants represent themselves with their face in a front or profile position. Bodies emerge with a varied degree of differentiation. More frequent elements are: trunk, upper and lower limbs, hands, feet, face, hair, eyes, mouth, recognition of pregnancy (prominent belly and transparency). Uncommon elements are: maternal smile, prominent breasts, nakedness, umbilical cord, placenta, uterus and the touch of the hands upon maternal belly. Paternal figure was present in a single case. Globally, the affective expression of the drawings seems basic and elementary.

A principal components analysis was performed and, after that, internal consistency analysis. This was done with data of the first moment because one of the goals was to study the relationship between the body image of pregnant women and maternal-fetus differentiation wich theoretically happens by the second trimester (Colman \& Colman, 1971). Besides that, participants at the second moment could be influenced by the repetition of drawings.

Data showed good qualities for factorial analysis (KMO $=.830$; Bartlett sfericity $\chi^{2}=5295.388$, $\mathrm{df}=595, \mathrm{p}=.000)$ and anti-image values were higher than .5 for all items excepting for three but being very close $(.471, .485$ and .498). With the original 46 items, nine factors were identified explaining $72.25 \%$ of total variance. This was not appropriate because from the fourth factor on each remaining factor only got two items. With Varimax rotation the initial factorial model emerged once more. A factorial analysis forced to four factors explained $54.238 \%$ of total variance and items were allocated by four factors according to factor loading (FL): F1, 19 items ( $F L=.872-.406$ ); F2, 10 items ( $\mathrm{FL}=.730-.476) ; \mathrm{F3}, 6$ items (FL $=.563-.428)$ and $\mathrm{F} 4,3$ items ( $\mathrm{FL}=.748-.433)$.

Finally, another factorial analysis with Varimax rotation and forced to four factors (Table 4) yelded a more balanced solution with four dimensions: F1- general representation of the imaginary baby (9 items), F2- representation of the maternal image (11 items), F3- detailed representation of the imaginary baby (7 items) and F4- recognition of pregnancy (7 items).

The general representation of the imaginary baby (F1) includes baby's: head-trunk differentiation, presence, placement inside the womb, face, transparency, lower limbs, upper limbs and human shape. The dimension representation of the maternal image (F2) includes mother's: face, trunk, mouth, hair, upper limbs, eyes, human shape, lower limbs, feet, hands and smile. Dimension detailed representation of the imaginary baby (F3) includes baby's: mouth, eyes, feet, hands, hair, nose and sex. Dimension recognition of pregnancy (F4) includes mother's breasts, nakedness, womb, touch of the belly and also placenta and pregnancy.

According to the analysis done for the last dimension, items mother touches belly and placenta were allocated to dimension recognition of pregnancy due to content analysis and because of internal consistency issues. Three factors present good internal consistency ( $F 1, \alpha=.966$; F2, $\alpha=.888$; F3, $\alpha=.846$ ) and the fourth presented a poor value (F4, $\alpha=.588$ ).

According to results of factorial analysis, variables of the general hypothesis were operationalized as follows: 1) maternal body image - F2; 2) maternal image about the inside baby - F3; 3) baby's position - known vs. unknown, cephalic vs. non-cephalic, fetal vs. non-fetal; 4) maternal recognition of pregnancy - F4 and 5) differentiation between mother's image and fetus' image - F1.

\section{Specific Hypothesis}

$\mathrm{H1}$ : Values of F1 (general representation of the imaginary baby) will not present significant changes between the second and the third trimester.

$\mathrm{H} 2$ : At the third trimester, F2 (representation of the maternal image) will present higher values than at the second trimester.

H3: F3 (detailed representation of the imaginary baby) at the third trimester will present higher values than at the second trimester. 


\section{PREGNANT WOMEN'S GRAPHIC REPRESENTATIONS: A NEW INSTRUMENT FOR THE ASSESSMENT OF THE BODY IMAGE DURING GESTATION}

H4: F4 (recognition of pregnancy) will not present significant differences between the second and the third trimesters.

H5: From the second to the third trimester, it will be observed an increase of the number of baby's known positions, cephalic positions and also fetal positions.

\section{Testing specific hypothesis}

Testing $\mathrm{H} 1, \mathrm{H} 2, \mathrm{H} 3$ and $\mathrm{H} 4$, an analysis of differences between $\mathrm{F} 1, \mathrm{~F} 2, \mathrm{~F} 3$ and $\mathrm{F} 4$ at the two trimesters is displayed in Table 5: a) $\mathrm{H} 1$ is confirmed because significant differences were not found $(Z=-.524, p>.05), b) \mathrm{H} 2$ is confirmed because a significant difference was found $(Z=-2.817, p \leq$ $.01), c) \mathrm{H} 3$ is not confirmed once that a significant difference was not found $(Z=-.499, p>.05)$ and d) $\mathrm{H} 4$ is confirmed because no significant differences were found $(Z=-.532, p>.05)$.

In order to test $\mathrm{H} 5$, differences about the items related to babies postion are presented in Table 6. As can be observed, $\mathrm{H} 5$ is partially confirmed once that: a) there is no increase in known positions $(Z=.000, p=1.000), b)$ there is a significant increase in cephalic positions $(Z=11.077, p=$ $.001)$ and $c)$ there is a significant increase in fetal positions $(Z=15.625, p=.000)$.

\section{DISCUSSION}

According to results, the representation of the maternal image (F2) undergoes significant changes once items of maternal body (lower limbs, upper limbs and feet) are more frequent in drawings of the third trimester than in the second; suggesting an enrichment of the body image as birth approaches. Important changes are observed about the baby's position once that by the third trimester cephalic positions and fetal positions are much more frequent than at the second becoming closer to reality; baby's position and location seem to have priority at the fantasy of the future mother. Concluding, the evolution of drawings of pregnancy appeals to the projection of the maternal image and to the anticipation of delivery.

Data seem to reinforce the theory of psychological development during pregnancy (Colman \& Colman, 1971) because: 1- recognition of pregnancy is about acceptance of pregnancy which is acquired by the first trimester and does not evolve after that; 2- differentiation between the mother and the fetus is achieved by the second trimerster and so it will not present changes comparatively to the last trimester; 3- psychological separation between mother and baby is achieved by the third trimester and differences between the two moments are observable in what respects to positions suggesting birth.

The primacy of the continent relatively to the content seems to emerge in drawings through the evolution of the maternal body image during the third trimester.

Our data also agree with the idea that the imagined baby is independent of the fetal image (Parquet \& Delcambre, 1980; Sá \& Biscaia, 2004) mostly during the second trimester when maternal projection seems to be more prominent relatively to the third trimester when the anticipation of the real baby becomes more compelling.

Stepping into relationships between, on one side, sociodemographic and clinical variables and, on the other side, drawing variables, some important aspects should be underlined (Table 7). By the second trimester, the number of gestational weeks when maternal perception of fetal movements begins correlates negatively with recognition of pregnancy, possibly because maternal perception of fetal activity triggers maternal-fetal differentiation. Parity is positively correlated with the general representation of the imaginary baby and with fetal position, both at the second trimester. These results showed that the higher the number of sons: a) the richer the general representation of the baby and b) more probable is the cephalic position. So, parity reinforces the investment of the imagined baby once that previous maternal experience facilitates projection relatively to a future baby. 
The number of spontaneous abortions and the representation of maternal image correlate significantly at both trimesters meaning that the higher the number of spontaneous abortions the higher the representation of maternal image at both moments.

This way, previous spontaneous abortions reinforce the investment of the maternal image by the second and the third trimesters as well as the detailed representation of the imagined baby by the third trimester. Possibly, there is an attempt of reparation and protection of the women's body image and of her inside baby. The total number of abortions seems able to influence maternal concerns, promoting an anticipation of delivery which increases representations of cephalic position at the second trimester; these women are less prone to fantasize about the imaginary baby and at the same time are prone to represent the baby in a position typical of the end of pregnancy.

Between the baby's position by the second trimester and the total of abortions we observed a positive and significant correlation; the higher the number of abortions the higher the probability for a cephalic position. This suggests that women with experience of abortions have higher concerns about the loss of pregnancy and anticipate details about delivery.

By the last trimester, the total number of abortions does not correlates significantly any more with the number of cephalic positions. Probably, at this moment the viability of pregnancy is ensured and concerns decrease; by the third trimester the cephalic position becomes more adecquate for the representation of obstetric reality.

Cephalic position also associates with parity. Once that cephalic position seems to anticipate birth this suggest that women who experienced previous labor and births seem to be concerned with the real aspects of reproduction. This suggest that women's experience about pregnancy, delivery and raising children prevents fantasy about the future baby. Possibly also these experiences induce the investment of a good deal of attention in children born previously to the present pregnancy.

The representation of the maternal image indicates the progression of the containing function during pregnancy. However it also may represent a defensive reparation induced by the experience of previous abortions. On one side, the representation of the imaginary baby may be influenced by previous experience of maternity (parity) but, on another side, the baby's cephalic position may indicate a defensive anticipation of delivery in the sequence of interruptions of past gestations.

These conclusions are based in data from a healthy sample. It would be interesting to question if this instrument would be equally useful in clinical populations as in culturally different populations.

\section{REFERENCES}

Bion, W. R., (1963). Learning from Experience. London: W. Heinemann.

Biscaia, J., (1990). Perder para Encontrar. Coimbra: Gráfica de Coimbra.

Biscaia, J. \& Sá, E., (1996). Dinâmica emocional na gravidez- contributo para uma estratégia de avaliação da personalidade através do desenho. Coimbra Médica, 15, 253-260.

Carvalho, M. E., (2011). O bebé imaginário, as memórias dos cuidados parentais e as representações sonoro-musicais na gravidez no estudo da representação da vinculação materna prénatal e da orientação para a maternidade. Doctoral Thesis in Clinical Psychology at the Lisbon University. http:// hdl.handle.net/10451/6597

Chang, S.-R., Chao, Y.-M., \& Kenney, N. J., (2006). I am a woman and I'm pregnant: body image of women in Taiwan during the third trimester of pregnancy. Birth, 33, 2, 147-153. DOI: 10.1111/j.0730-7659.2006.00087.x.

Colman, A. \& Colman, L., (1971). Pregnancy: The Psychological Experience. New York: Herder \& Herder, Inc. 
Graffar, M., (1956). Une méthode de classification sociale d'échantillons de population. Courrier, $6(8), 455-459$.

Harris, D. B., (1981). El Teste de Goodenough: revisión, ampliación y actualización. BarcelonaBuenos Aires: Paidos.

Huang, H.-C., Wang, S.-Y., \& Chen, C.-H., (2004). Body image, maternal fetal attachment and choice of infant feeding method: A study in Taiwan. Birth, 31(3), 183-188. http://dx.doi.org/10.1111/j.0730-7659.2004.00303.x

Kolck, O. L. van, (1984). Testes projetivos gráficos no diagnóstico psicológico. São Paulo: EPU.

Mendes, I., (2002). Ligação materno-fetal. Lisboa: Quarteto.

Machover, K. A., (1949). Personality projection in the drawing of the human figure: a method of personality investigation. Springfield, IL: Charles C. Thomas Publisher.

Parquet, P.-J., \& Delcambre, G., (1980). Dessins de corps d'enfants imaginés pendant la grossesse. In Rapaport (Ed.), Les Cahiers du Nouveau-Né, Corps de Mère, Corps d'Enfant 4, 201- 218.

Raphael-Leff, J., (2009). Psychological Processes of Childbearing. London: Anna Freud Centre. http://ethos.bl.uk/OrderDetails.do?uin=uk.bl.ethos.397890

Riazuelo, H., (2004). Les specificités de l'attente d'un second enfant. In (Eds.) S. Missonier, B. Golse \& M. Soulé, La grossesse, l'enfant virtuel et la parentalité (pp. 145-159). Paris: PUF.

Riazuelo, H., (2010). Représentations maternelles au cours d'une première et d'une seconde grossesse. Neuropsychiatrie de l'enfance et de l'adolescence. 58, 448-455. http://dx.doi.org/10.1016/j.neurenf.2010.05.006

Sá, E., \& Biscaia, J., (2004). A gravidez no pensamento das mães - contributo para a avaliação da gravidez através do desenho. In Sá, E. (Ed.), A Maternidade e o Bebé (pp. 13-21). Lisboa: Fim do Século.

Lebovici, S., (1983). Le nourrisson, la mère et le psychanalyste. Paris: Le Centurion.

Silva, M. G., (2006). "Ecografia do Psiquismo", o primeiro internamento - no interior da barriga da mãe. Cadernos de Educação da Infância, 78, Agosto, 10-14.

Swan-Foster, N., Foster, S., \& Dorsey, A., (2003). The use of the human figure drawing with pregnant women. Journal of Reproductive and Infant Psychology, 21(4), 293-307.

DOI: 10.1080/02646830310001622105

Tolor, A., \& Digrazia, P.V., (1977). The body image of pregnant women as reflected in their human figure drawings, Journal of Clinical Psychology, 33(2), 566-571.

Watson, B., Fuller-Tyszkiewicz, M., Broadbent, J., \& Skouteris, H., (2015). The meaning of body image experiences during the perinatal period: A systematic review of the qualitative literature. Body Image, 14, 102-113. http://dx.doi.org/10.1016/i.bodyim.2015.04.005

Watson, B., Broadbent, J., Skouteris, H., \& Fuller-Tyszkiewicz, M., (2016). A qualitative exploration of body image experiences of women progressing through pregnancy. Women and Birth, 29, $72-$ 79.

doi:10.1016/j.wombi.2015.08.00 
Table 1. Descriptive statistics of sociodemographic data of the sample $(N=202)$.

\begin{tabular}{|c|c|c|c|}
\hline Variables & & $N$ & $\%$ \\
\hline \multirow[t]{2}{*}{ nationality } & Portuguese & 187 & 92.6 \\
\hline & other & 15 & 7.4 \\
\hline \multirow[t]{4}{*}{ marital status } & single* & 7 & 3.5 \\
\hline & married & 138 & 68.3 \\
\hline & living out of wedlock & 56 & 27.7 \\
\hline & divorced* & 1 & .5 \\
\hline \multirow[t]{4}{*}{ occupational level } & Graffar I & 70 & 34.7 \\
\hline & Graffar II-III & 119 & 58.9 \\
\hline & Graffar IV-V & 13 & 6.4 \\
\hline & & $\mathrm{M}$ & SD \\
\hline age & & 32.27 & 3.89 \\
\hline education & & 15.6 & 3.02 \\
\hline marital life long & & 8.9 & 5.15 \\
\hline
\end{tabular}

*Cohabiting with the father of the baby

Table 2. Obstetrical life and clinical data of the present pregnancy $(N=202)$

\begin{tabular}{lcc}
\hline & $\mathrm{M}$ & $\mathrm{SD}$ \\
\hline previous pregnancies & .82 & 1.02 \\
parity & .54 & .71 \\
voluntary abortions & .03 & .18 \\
spontaneous abortions & .21 & .52 \\
abortions by medical advice & .04 & .23 \\
previous sonograms & 2.95 & 1.89 \\
medical appointments & 4.04 & 1.27 \\
gestational age at the first consultation & 6.97 & 1.83 \\
beginning of perception of fetal movements & 18.49 & 2.54 \\
\hline
\end{tabular}


Table 3. Data about the present pregnancy and about the future baby $(N=202)$.

\begin{tabular}{llcc}
\hline & & frequency & $\%$ \\
\hline desire of pregnancy & no & 1 & .5 \\
& yes & 201 & 99.5 \\
planned pregnancy & no & 37 & 18.3 \\
& yes & 165 & 81.7 \\
risk factors & no & 168 & 83.2 \\
& yes & 34 & 16.8 \\
traumatic events & no & 173 & 85.6 \\
& yes & 29 & 14.4 \\
baby's gender & doesn't know & 42 & 20.8 \\
& o & 70 & 34.7 \\
reaction to baby's & o & 90 & 44.6 \\
gender & unresponsive & 15 & 7.4 \\
& positive & 142 & 70.3 \\
preference about baby's & negative & 4 & 2.0 \\
gender & yes & 120 & 59.4 \\
which preference & female & 82 & 40.6 \\
& male & 56 & 27.7 \\
baby's name already & no & 26 & 12.9 \\
choosed & yes & 61 & 30.2 \\
\hline
\end{tabular}

Table 4: Factorial analysis (46 items) with Varimax rotation and forced to four factors.

\begin{tabular}{|c|c|c|c|c|}
\hline & F1* & $\mathrm{F} 2 * *$ & $\mathrm{~F} 3 * * *$ & $\mathrm{~F} 4 * * * *$ \\
\hline baby's head-trunk differentiation & .921 & & & \\
\hline baby present & 912 & & & \\
\hline baby inside the womb & .909 & & & \\
\hline baby's face & .907 & & & \\
\hline transparency & .900 & & & \\
\hline baby's lower limbs & .811 & & & \\
\hline baby's upper limbs & .802 & & & \\
\hline baby's human shape & .785 & & & \\
\hline mother's face & & .821 & & \\
\hline mother's trunk & & .805 & & \\
\hline mother's mouth & & .786 & & \\
\hline mother's hair & & .780 & & \\
\hline mother's upper limbs & & .766 & & \\
\hline mother's eyes & & .764 & & \\
\hline mother's human shape & & .705 & & \\
\hline mother's lower limbs & & .698 & & \\
\hline mother's feet & & .574 & & \\
\hline mother's hands & & .540 & & \\
\hline mother's smile & & .447 & & \\
\hline baby's mouth & & & .746 & \\
\hline baby's eyes & & & .733 & \\
\hline baby's feet & & & .717 & \\
\hline baby's hands & & & .709 & \\
\hline baby's hair & & & .679 & \\
\hline baby's nose & & & .635 & \\
\hline baby's sex & & & .480 & \\
\hline mother's breasts & & & & .766 \\
\hline mother's nakedness & & & & .660 \\
\hline mother's womb & & & & .427 \\
\hline mother touches belly & & & & .426 \\
\hline placenta & & & & .407 \\
\hline pregnancy & & & & .402 \\
\hline
\end{tabular}


Table 5. Differences between the second trimester $(N=202)$ and the third trimester $(N=159)$ according to the dimensions of the DPS.

\begin{tabular}{llcccccccc}
\hline Dimensions of DPS & trimesters & $\mathrm{n}$ & $\mathrm{M}$ & $\mathrm{SD}$ & Min & Max & $\begin{array}{c}\text { Negative } \\
\text { differences }\end{array}$ & $\begin{array}{c}\text { Positive } \\
\text { differences }\end{array}$ & $\mathrm{Z}$ \\
\hline $\mathrm{F} 1 *$ & & & & & & & \\
& II trimester & 199 & 5.24 & 3.39 & .00 & 8.00 & 33 & 34 & -.524 \\
$\mathrm{~F} 2 * *$ & III trimester & 159 & 5.33 & 3.43 & .00 & 8.00 & & & \\
& II trimester & 202 & 8.04 & 3.15 & .00 & 11.00 & 34 & 60 & $-2.817^{\mathrm{a}}$ \\
$\mathrm{F} 3 * * *$ & III trimester & 159 & 8.82 & 2.76 & .00 & 11.00 & & & \\
& II trimester & 199 & 1.26 & 1.872 & .00 & 7.00 & 36 & 40 & -.499 \\
$\mathrm{~F} 4 * * * *$ & III trimester & 159 & 1.53 & 2.04 & .00 & 7.00 & & & \\
& II trimester & 202 & 2.52 & .95 & .00 & 4.00 & 26 & 23 & -.532 \\
\hline$*$ & III trimester & 159 & 2.48 & .93 & .00 & 4.00 & & & \\
\hline
\end{tabular}

* F1 - general representation of the imaginary baby; ${ }^{* *}$ F2 - representation of the maternal image; ${ }^{* *}$ F3 -detailed representation of the imaginary baby; **** $\mathrm{F} 4$ - recognition of pregnancy

${ }^{\mathrm{a}} \mathrm{p} \leq .01$.

Table 6. Frequencies, percentages and differences between items of the DPS at the second $(n=202)$ and the third trimesters $(n=159)$

\begin{tabular}{lccccccc}
\hline Baby's Position & \multicolumn{2}{c}{$\begin{array}{c}\text { Second trimester } \\
(\mathrm{n}=202)\end{array}$} & $\begin{array}{c}\text { Third trimester } \\
(\mathrm{n}=159)\end{array}$ & $\mathrm{Z}$ & $\mathrm{DF}$ & $\mathrm{P}$ \\
\cline { 2 - 8 } & $\mathrm{n}$ & $\%$ & $\mathrm{n}$ & $\%$ & & & \\
\hline unknown & 66 & 32.7 & 49 & 30.8 & .000 & 1 & 1.000 \\
known & 136 & 67.33 & 110 & 69.18 & & & \\
non-cephalic & 39 & 19.3 & 9 & 5.7 & 11.077 & 1 & $.001 *$ \\
cephalic & 6 & 3.0 & 51 & 32.1 & & & \\
non-fetal & 90 & 44.6 & 48 & 30.2 & 15.625 & 1 & $.000 *$ \\
fetal & 45 & 22.28 & 60 & 37.74 & & & \\
\hline \multicolumn{1}{c}{$* 0.05$} & & & & & &
\end{tabular}

Table 7. Correlations between DPS dimensions and sociodemograpfic and clinical variables

\begin{tabular}{|c|c|c|c|c|c|}
\hline $\begin{array}{c}\text { DPS dimensions } \\
\text { Sociodemographics }\end{array}$ & $\begin{array}{c}\text { F1 } \\
\text { second } \\
\text { trimester }\end{array}$ & $\begin{array}{c}\text { F2 } \\
\text { second } \\
\text { trimester }\end{array}$ & $\begin{array}{c}\text { F2 } \\
\text { third trimester }\end{array}$ & $\begin{array}{c}\text { F4 } \\
\text { second } \\
\text { trimester }\end{array}$ & $\begin{array}{c}\text { fetal position } \\
\text { second trimester }\end{array}$ \\
\hline $\begin{array}{l}\text { spontaneous } \\
\text { abortions }\end{array}$ & & $\begin{array}{l}r=.2 \\
(.01)^{*}\end{array}$ & $\begin{array}{l}r=.26 \\
(.001)^{*}\end{array}$ & & \\
\hline parity & $\begin{array}{l}\mathrm{r}=.19 \\
(.01)^{*}\end{array}$ & & & & $\begin{array}{l}r=.311 \\
(.000)^{* *}\end{array}$ \\
\hline $\begin{array}{l}\text { beginning of } \\
\text { maternal } \\
\text { perception of fetal } \\
\text { movements }\end{array}$ & & & & $\begin{array}{c}r=-.16 \\
(.05)^{*}\end{array}$ & \\
\hline total abortions & & & & & $\begin{array}{l}r=.349 \\
(.000)^{* *}\end{array}$ \\
\hline
\end{tabular}

F1- general representation of the imaginary baby; F2 - representation of the maternal image; F4 recognition of pregnancy.

$*(\mathrm{p} \leq)$

$* *(\mathrm{p}=)$ 
